\title{
Quantifying the effect of enflurane on atracurium infusion requirements
}

The present study was designed to evaluate the interaction between atracurium and enflurane in 40 adult surgical patients using closed-loop feedback control of infusions of atracurium. Anaesthesia was induced with thiopentone and fentanyl and intubation was facilitated with atracurium $0.5 \mathrm{mg} \cdot \mathrm{kg}^{-1}$ lean body mass. During the first $90 \mathrm{~min}$, anaesthesia was maintained with nitrous oxide in oxygen (2:1) and fentanyl. For the following 90 min the patients were randomly assigned to receive enflurane at different end-tidal concentrations: Group I, control, fentanyl-nitrous oxide anaesthesia; Group II, enflurane $0.3 \%$ nitrous oxide; Group III, enflurane 0.6\%-nitrous oxide; Group $I V$, enflurane $0.9 \%$-nitrous oxide. The possible interaction of atracurium with enflurane was quantified by determining the asymptotic steady-state rate of infusion ( $\left.I_{s s}\right)$ of atracurium necessary to produce a constant $90 \%$ neuromuscular block. This was accomplished by applying nonlinear curve fitting to data on the cumulative dose requirements. Every patient served as his/her own control and the changes in the infusion rates were determined individually. Patient characteristics and controller performance, i.e., the ability of the controller to maintain the neuromuscular blockade constant at the setpoint, did not differ among groups. In Group II $I_{s s}$ decreased from $0.33 \pm 0.12$ to $0.26 \pm 0.08 \mathrm{mg} \cdot \mathrm{kg}^{-1} \cdot \mathrm{hr}^{-1}(P<0.01)$, in Group III from $0.32 \pm$ to 0.12 to $0.24 \pm 0.08 \mathrm{mg} \cdot \mathrm{kg}^{-1} \cdot \mathrm{hr}^{-1}(P<0.001)$ and in Group IV from $0.29 \pm 0.09$ to $0.21 \pm 0.09 \mathrm{mg} \cdot \mathrm{kg}^{-1} \cdot \mathrm{hr}^{-1}$

\section{Key words}

ANAESTHETICS, VOLATILE: enflurane; NEUROMUSCULAR RELAXANTS: atracurium; PHARMACODYNAMICS: interaction.

From the Department of Anaesthesia, University of Helsinki, FIN-00290 Helsinki, Finland.

Address correspondence to: Dr. Maija Kansanaho,

Department of Anaesthesia, University of Helsinki,

Haartmaninkatu 4, FIN-00290 Helsinki, Finland.

This study was supported by the Paulo Foundation,

Helsinki, Finland.

Accepted for publication 16th October, 1994.
$(P<0.001)$. In the control group atracurium requirements remained unchanged throughout the study. Enflurane reduces atracurium requirements in a dose-dependent manner. During enflurane anaesthesia the rate of atracurium infusion should be reduced but because of interindividual differences the monitoring of the neuromuscular function is important to ensure the appropriate level of neuromuscular block.

Cette étude vise à évaluer avec un contrôle de feed-back fermé des perfusions d'atracurium linteraction de l'atracurium avec l'enflurane chez 40 opérés adultes. L'anesthésie est induite au thiopentone et au fentanyl et lintubation est réalisée sous atracurium $0,5 \mathrm{mg} \cdot \mathrm{kg}^{-1}$ de masse corporelle maigre. Pendant les premières $90 \mathrm{~min}$, l'anesthésie est entretenue avec du protoxyde d'azote en oxygène (2:I) et du fentanyl. Pendant les $90 \mathrm{~min}$ suivantes, les patients sont assignés au hasard pour recevoir de l'enflurane à différentes concentrations téléexpiratoires: groupe $I$, contrôle, anesthésie au fentanyl-protoxyde d'azote; groupe II, enflurane 0,3\%-protoxyde d'azote; groupe $I I$, enflurane $0,6 \%$ protoxyde d'azote, groupe IV. enflurane $0,9 \%$-protoxyde d'azote. Linteraction éventuelle de l'atracurium avec l'enflurane est quantifiée à l'état d'équilibre par la détermination de la vitesse de perfusion asymptomatique $\left(I_{s s}\right)$ d'atracurium nécessaire pour produire un bloc neuromusculaire à 90\%. Ceci est réalisé en appliquant le lissage non linéaire à la courbe des données des besoins cumulatifs. Chaque patient est son propre contrôle et les modifications apportées à la perfusion sont déterminées individuellement. Les caractéristiques du patient et la performance du contrôleur, c'est-à-dire l'habileté du contrôleur à maintenir la constance du bloc neuromusculaire au niveau prédéterminé, ne differe pas entre les groupes. Dans le groupe II, l'I $I_{s s}$ diminue de $0,33 \pm 0,12$ à $0,26 \pm 0,08 \mathrm{mg} \cdot \mathrm{kg}^{-1} \cdot \mathrm{hr}^{-1}$ $(P<0.01)$, dans le groupe III de 0,32 $\pm 0,12$ à $0,24 \pm 0,08$ $\mathrm{mg} \cdot \mathrm{kg}^{-1} \cdot \mathrm{hr}^{-1}(P<0,001)$ et dans le groupe IV de 0,29 \pm 0,09 à $0,21 \pm 0,09 \mathrm{mg} \cdot \mathrm{kg}^{-1} \cdot \mathrm{hr}^{-1}(P<0,001)$. Dans le groupe contrôle, les besoins en atracurium demeurent inchangés pendant toute l'étude. L'enfluane diminue les besoins d'atracurium proportionnellement à la dose. Pendant l'anesthésie à l'enflurane la dose d'atracurium devrait être diminuée mais à cause des différences entre individus, le monitorage de la fonction neuromusculaire est important pour assurer un degré de bloc adéquat. 
Atracurium is a nondepolarizing neuromuscular blocking drug with an intermediate duration of action and a relatively short elimination half-life. Therefore, if it is used during long anaesthetics, it is likely to be administered as a continuous infusion. ${ }^{1,2}$ The interaction of muscle relaxants and volatile anaesthetics depends both on the neuromuscular blocking drug and inhalational anaesthetic. The intermediate-acting relaxants appear to be potentiated less by volatile anaesthetics than are the older long-acting drugs. ${ }^{\prime}$ Although there is some information about the interaction of inhalational anaesthetics and atracurium given by continuous infusion, ${ }^{3-6}$ the information of different concentrations of volatile anaesthetics on atracurium infusion requirements is lacking.

This study was designed to quantify the effect of clinically relevant concentrations of enflurane on atracurium infusion requirements and to investigate the possible time dependence of this interaction. We used the technique of closed-loop feedback control of atracurium infusion to maintain a steady neuromuscular blockade of $90 \%$. The effect of enflurane on the atracurium infusion requirements was quantified by determining the asymptotic steady-state infusion rates necessary to produce $90 \%$ neuromuscular blockade at different levels of enflurane anaesthesia.

\section{Methods}

With approval of the local Medical Ethics Committee and after obtaining informed consent, 40 adult general surgical patients, ASA physical status 1-3, aged 23-68 $y r$, were studied. Patients with hepatic or renal dysfunction, neuromuscular disease or patients receiving concomitant medication known to affect neuromuscular transmission were excluded from the study.

For premedication patients received oxycodone hydrochloride $0.14 \mathrm{mg} \cdot \mathrm{kg}^{-1}$ and $12.5-25 \mathrm{mg}$ promethazine hydrochloride im one hour before the start of anaesthesia. A standard dose of glycopyrrolate $0.2 \mathrm{mg} i v$ was given to all patients prior to induction of anaesthesia. Anaesthesia was induced with thiopentone $3-6 \mathrm{mg} \cdot \mathrm{kg}^{-1}$ and fentanyl $0.1-0.2 \mathrm{mg}$. During the first $90 \mathrm{~min}$, anaesthesia was maintained with nitrous oxide in oxygen (2:1). Additional fentanyl $(0.05-0.2 \mathrm{mg})$ or thiopentone $(50-100$ $\mathrm{mg}$ ) bolus doses were given when anaesthesia was thought to be inadequate as judged by motor responses, lacrimation or changes in the cardiovascular variables $(>15 \%$ increase in systolic blood pressure).

After $90 \mathrm{~min}$ the patients were randomly assigned to one of the four study groups. In the control group (Group I) anaesthesia was continued with fentanyl-nitrous oxide. In the other groups we administered enflurane at different end-tidal concentrations: $0.3 \%$ (Group II), $0.6 \%$ (Group III) and $0.9 \%$ (Group IV). Together with $67 \%$ nitrous oxide the administration of enflurane resulted in MAC values of $0.8,1.0$ and 1.2 in Groups II-IV, respectively. The second study period lasted also $90 \mathrm{~min}$. After the 180-min study period anaesthesia was continued according to clinical needs. The monitoring included noninvasive or invasive blood pressure, continuous ECG, minute ventilation, ventilatory rate, capnography, inspiratory $\mathrm{O}_{2}$ concentration, volatile anaesthetic end-tidal concentration, airway pressure and pulse oximetry. Palmar skin temperature was measured and kept $>32^{\circ} \mathrm{C}$. End-tidal $\mathrm{CO}_{2}$ tension was maintained at $4.5-5 \mathrm{kPa}$.

The degree of neuromuscular blockade was assessed electromyographically every $20 \mathrm{sec}$ with a Relaxograph ${ }^{\circledR}$ (Datex, Helsinki, Finland) neuromuscular transmission monitor. Surface electrodes were placed over the ulnar nerve on the wrist to stimulate the nerve supramaximally with a train-of-four sequence (frequency of stimuli, $2 \mathrm{~Hz}$; pulse width $100 \mu \mathrm{s}$ ) and over the first interosseus muscle of the hand and on the base of the index finger to record the compound electromyogram. The stimulus output was a rectangular wave with a current range of $0-70 \mathrm{~mA}$ and the machine calibrated automatically by searching for the optimum signal levels before setting the supramaximal level. The degree of neuromuscular blockade was defined as the ratio of the measurement of the first twitch in the train-of-four sequence $\left(T_{1}\right)$ to the corresponding control value. The first calibration of the neuromuscular monitoring device was carried out immediately after the induction of anaesthesia. Then, a stable calibration signal was awaited before the second calibration. The interval between the two calibrations was 5-10 min.

After the second calibration, all patients received atracurium $0.5 \mathrm{mg}$ calculated per lean body mass ${ }^{7}$ and their tracheas were intubated. The initial bolus dose was followed by a continuous infusion of atracurium through an indwelling venous catheter in a forearm vein. The infusion rate was controlled by a model-driven closedloop feedback system as described previously. ${ }^{8}$ An infusion pump (Fresenius infusomat CP-IS ${ }^{\circledR}$, Fresenius AG, Bad Homburg, Germany) and the Relaxograph ${ }^{\circledR}$ were attached to a Compaq ${ }^{\circledR}$ Portable 386 Computer (Compaq Computer Corporation, Houston, TX, USA) by means of a serial RS232 interface. The desired neuromuscular blockade was set to $90 \%\left(\mathrm{~T}_{1}=10 \%\right.$ from control). Controller performance was measured by calculating the mean offset and the mean standard deviation from the set-point during feedback infusion. ${ }^{9}$ During the close-loop feedback infusion of atracurium, the measured values for effect and the infusion rates were saved on computer. To estimate the asymptotic steady-state rate of infusion $\left(\mathrm{I}_{\mathrm{ss}}\right)$, we used nonlinear curve fitting for both of the 90 -min study periods. ${ }^{10}$ 
TABLE I Patient characteristics

\begin{tabular}{|c|c|c|c|c|c|}
\hline Group & $\begin{array}{l}\text { No } \\
(M / F)\end{array}$ & $\begin{array}{l}\text { ASA physical } \\
\text { status } \\
(1 / 2 / 3)\end{array}$ & $\begin{array}{l}\text { Age } \\
\text { (yr) }\end{array}$ & $\begin{array}{l}\text { Weight } \\
\text { (kg) }\end{array}$ & $\begin{array}{l}\text { Height } \\
(\mathrm{cm})\end{array}$ \\
\hline $\begin{array}{l}\mathrm{N}_{2} \mathrm{O} / \mathrm{O}_{2} \\
(2: 1)\end{array}$ & $\begin{array}{l}10 \\
(6 / 4)\end{array}$ & $7 / 3 / 0$ & $42 \pm 15$ & $66 \pm 14$ & $169 \pm 7$ \\
\hline $\begin{array}{l}+0.3 \% \\
\text { enflurane }\end{array}$ & $\begin{array}{l}10 \\
(5 / 5)\end{array}$ & $5 / 4 / 1$ & $47 \pm 14$ & $73 \pm 12$ & $174 \pm 9$ \\
\hline $\begin{array}{l}+0.6 \% \\
\text { enflurane }\end{array}$ & $\begin{array}{l}10 \\
(4 / 6)\end{array}$ & $3 / 6 / 1$ & $47 \pm 14$ & $73 \pm 16$ & $170 \pm 8$ \\
\hline $\begin{array}{l}+0.9 \% \\
\text { enflurane }\end{array}$ & $\begin{array}{l}10 \\
(6 / 4)\end{array}$ & $0 / 8 / 2$ & $50 \pm 12$ & $71 \pm 15$ & $167 \pm 7$ \\
\hline$P$ & $0.776 \dagger$ & $0.074 \dagger$ & $0.613^{*}$ & $0.646^{*}$ & $0.294^{*}$ \\
\hline
\end{tabular}

Values are mean $\pm S D$.

*Determined by one-way ANOVA.

$\dagger$ Determined by Chi-Square test.

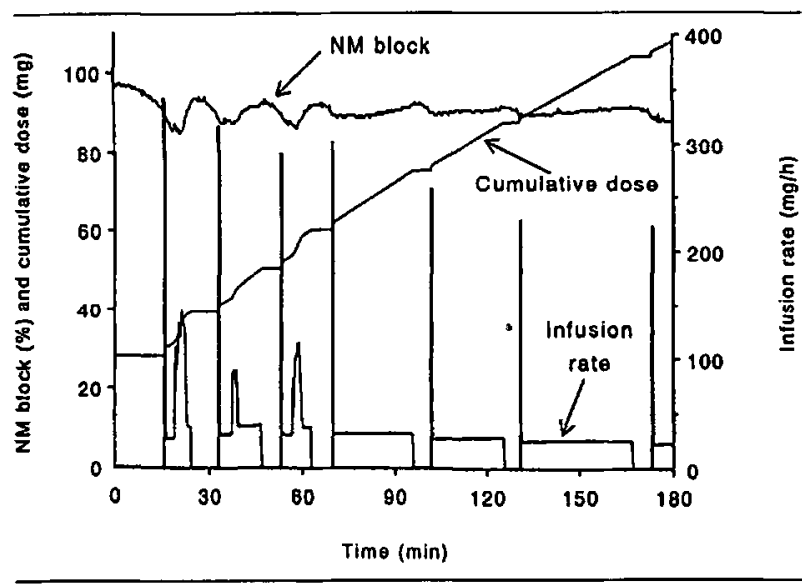

FIGURE 1 Data for one representative patient in the group anaesthetized with fentanyl-nitrous oxide for the initial period of 90 $\mathrm{min}$ and then with enflurane ( $0.9 \%$ end-tidal concentration)-ritrous oxide.

\section{Cumulative dose of atracurium $=\mathrm{D}\left(1-\mathrm{e}^{\mathrm{kt}}\right)+\mathrm{I}_{\mathrm{ss}} \mathrm{t}$}

where $\mathrm{D}=$ amount of atracurium contained in its apparent distribution volume, $\mathrm{k}=$ relative rate of distribution of atracurium, $\mathrm{I}_{\mathrm{ss}}=$ asymptotic steady-state rate of infusion of atracurium, $t=$ duration of atracurium administration.

In this study every patient served as his/her own control and the changes in the atracurium infusion rates from the first $\left(\mathrm{I}_{\mathrm{ss}}\right)$ to the second $\left(\mathrm{I}_{\mathrm{ss} 2}\right)$ 90-min study period were determined individually by determining the $I_{\mathrm{ss} 2} / I_{\mathrm{ss} 1}$ ratio. To investigate the possible time-dependence of the interaction of atracurium and enflurane, we also compared the cumulative dose requirements of atracurium at 30 min intervals during the second 90 -min study period.

For statistical analysis we used analysis of variance and Chi-square test to compare the variables among groups. Following analysis of variance, a posteriori testing was done with Fisher's least significant difference test. Linear regression analysis was used for the analysis of possible linear correlation between end-tidal enflurane concentration and atracurium infusion requirements. Student's t-test for paired samples was used to compare $I_{\text {ss }}$ and $I_{s s 2}$ values and the values for the palmar skin temperature at the end of the first and second study period in each group. $P<0.05$ was considered to indicate statistically signficant differences. All results are given as mean $\pm \mathrm{SD}$.

\section{Results}

The patient characteristics are shown in Table I. The study groups did not differ with regard to age, weight, height or ASA physical status. Figure 1 shows an example of the time course of neuromuscular blockade and the cumulative dose requirements of atracurium for one patient belonging to Group IV. Table II shows the average controller performance, $I_{s s}$ for both of the 90 min study periods and the cumulative infusion requirements of atracurium at $30 \mathrm{~min}$ intervals during the second study period for the four groups. Controller performance, peripheral skin temperature and end-tidal carbon dioxide tension were similar in all groups.

During the first 90 -min study period when no volatile anaesthetic was given, the $I_{s s}$ values were at the same level. During the second study period, when enflurane was added, the $I_{s s}$ values decreased. In Group II (enflurane $0.3 \%$ ) the $I_{\text {ss }}$ decreased from $0.33 \pm 0.12$ to 0.26 $\pm 0.08 \mathrm{mg} \cdot \mathrm{kg}^{-1} \cdot \mathrm{hr}^{-1}$ (Student's t test; $P<0.01$ ), in group III (enflurane $0.6 \%$ ) from $0.32 \pm 0.12$ to $0.24 \pm$ $0.08 \mathrm{mg} \cdot \mathrm{kg}^{-1} \cdot \mathrm{hr}^{-1}(P<0.001)$ and in Group IV (enflurane $0.9 \%$ ) from $0.29 \pm 0.09$ to $0.21 \pm 0.09$ $\mathrm{mg} \cdot \mathrm{kg}^{-1} \cdot \mathrm{hr}^{-1}(P<0.001)$. In the control group the atracurium infusion requirements remained at the same 
TABLE II Controller performance, cumulative atracurium requirements during the 2 nd 90 -min study period and steady-state rate of infusion of atracurium during fentanyl-nitrous oxide and different levels of enflurane-nitrous oxide anaesthesia

\begin{tabular}{|c|c|c|c|c|c|c|c|c|c|c|}
\hline \multirow[b]{3}{*}{ Group } & \multicolumn{4}{|c|}{ Controller performance } & \multicolumn{2}{|c|}{$\begin{array}{l}\text { Rate of infusion of } \\
\text { atracurium* } \\
\left(\mathrm{mg} \cdot \mathrm{kg}^{-1} \cdot \mathrm{hr}^{-1}\right)\end{array}$} & \multirow{3}{*}{$\begin{array}{l}I_{s s 2} / I_{s s I} \\
\text { ratio }\end{array}$} & \multirow{2}{*}{\multicolumn{3}{|c|}{$\begin{array}{l}\text { Cumulative atracurium requirements } \\
\text { during the } 2 \text { nd } 90 \text { min study period } \\
\text { (mg) }\end{array}$}} \\
\hline & \multicolumn{2}{|c|}{ Offset from the set-point (\%) } & \multicolumn{2}{|c|}{$S D$ from set-point (\%) } & \multirow{2}{*}{$\begin{array}{l}1 s t 90 \mathrm{~min} \\
\left(I_{s s l}\right)\end{array}$} & \multirow{2}{*}{$\begin{array}{l}\text { 2nd } 90 \min \\
\left(I_{s s 2}\right)\end{array}$} & & & & \\
\hline & $1 s t 90 \mathrm{~min}$ & 2nd $90 \mathrm{~min}$ & 1 st $90 \mathrm{~min}$ & $2 n d 90 \mathrm{~min}$ & & & & $0-30 \mathrm{~min}$ & $30-60 \min$ & $60-90 \mathrm{~min}$ \\
\hline $\begin{array}{l}\mathrm{N}_{2} \mathrm{O} / \mathrm{O}_{2} \\
(2: 1)\end{array}$ & $0.5 \pm 2.1$ & $0.2 \pm 1.9$ & $3.6 \pm 2.1$ & $1.8 \pm 1.9$ & $0.34 \pm 0.08$ & $0.34 \pm 0.07$ & $1.01 \pm 0.09$ & $11.0 \pm 3.0$ & $11.2 \pm 4.5$ & $10.9 \pm 4.2$ \\
\hline $\begin{array}{l}+0.3 \% \\
\text { enflurane }\end{array}$ & $0.6 \pm 1.5$ & $0.6 \pm 0.8$ & $3.2 \pm 1.5$ & $1.7 \pm 0.8$ & $0.33 \pm 0.12$ & $0.26 \pm 0.08$ & $0.80 \pm 0.12$ & $9.9 \pm 4.9$ & $10.2 \pm 4.7$ & $9.5 \pm 2.7$ \\
\hline $\begin{array}{l}+0.6 \% \\
\text { enflurane }\end{array}$ & $0.9 \pm 1.0$ & $0.7 \pm 0.6$ & $3.2 \pm 1.0$ & $1.6 \pm 0.6$ & $0.32 \pm 0.12$ & $0.24 \pm 0.08$ & $0.77 \pm 0.09$ & $9.1 \pm 3.2$ & $8.6 \pm 2.9$ & $8.3 \pm 3.0$ \\
\hline $\begin{array}{l}+0.9 \% \\
\text { enflurane }\end{array}$ & $0.8 \pm 0.9$ & $1.0 \pm 0.7$ & $2.9 \pm 0.9$ & $1.7 \pm 0.7$ & $0.29 \pm 0.09$ & $0.21 \pm 0.09$ & $0.71 \pm 0.11$ & $7.3 \pm 2.6$ & $6.7 \pm 2.7$ & $7.2 \pm 2.1$ \\
\hline$P \dagger$ & 0.782 & 0.083 & 0.720 & 0.959 & 0.726 & 0.007 & $<0.001$ & 0.140 & 0.062 & 0.060 \\
\hline
\end{tabular}

Values are mean $\pm S D$.

*Asymptotic steady-state rate of infusion of atracurium calculated per body weight.

$\dagger$ Determined by one way ANOVA

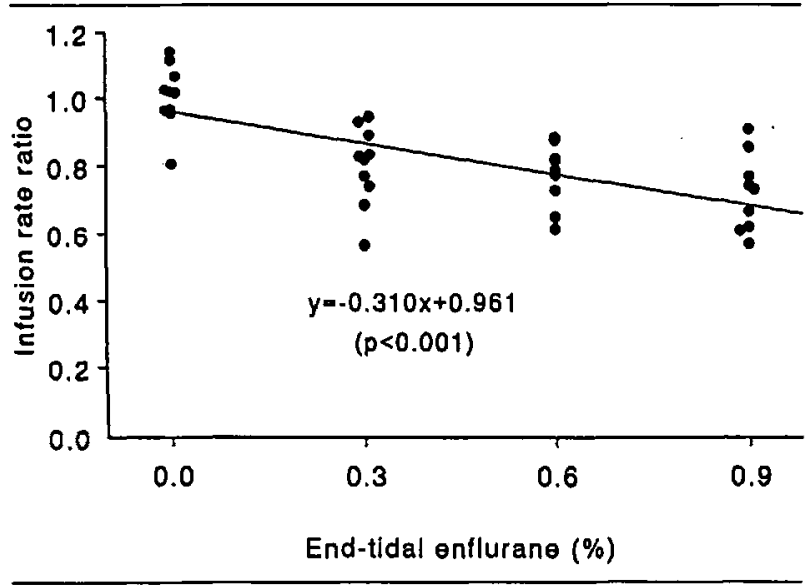

FIGURE 2 Ratio of the steady-state rate of infusion of atracurium during the 90 -min period of enflurane-nitrous oxide anaesthesia $\left(I_{s s}\right)$ to the corresponding rate of infusion $\left(\mathrm{I}_{\mathrm{ss}}\right)$ during $90 \mathrm{~min}$ control period when the same patients were anaesthetized with fentanyl-nitrous oxide. Enflurane was administered at end-tidal concentrations of $0,0.3$, 0.6 and $0.9 \%$.

level for the whole 180-min study period. Linear regression analysis revealed a linear relationship between the end-tidal enflurane concentration and the $I_{\mathrm{ss} 2} / I_{\mathrm{ss}}$-ratio (Figure 2). The $I_{s s 2} / I_{s s} 1$-ratio of the control group differed significantly from all the other groups and Group II differed from Group IV. According to analysis of variance, the cumulative atracurium dose requirements calculated at 30 -min intervals during the second 90 -min study period were similar in all groups.

\section{Discussion}

The steady-state infusion rate of atracurium was found to decrease linearly when end-tidal enflurane concentration was increased, although the differences in atracurium infusion requirements among the groups receiving $0.3 \%$, $0.6 \%$ or $0.9 \%$ end-tidal enflurane were very small and statistically significant only between Groups II and IV. Adding $0.3 \%$ end-tidal enflurane decreased the infusion rate by $20 \%, 0.6 \%$ enflurane by $23 \%$, and $0.9 \%$ enflurane by $29 \%$. In the control group the atracurium infusion requirements remained unchanged during both of the 90min study periods. However, the interindividual differences were large. For example, in Group IV there were patients in whom enflurane decreased the infusion rate over $40 \%$ and patients in whom there was almost no change.

Compared with our previous study with vecuronium, " atracurium infusion requirements are less affected by enflurane. For example, $0.9 \%$ enflurane decreased the infusion rate of vecuronium by $54 \%$ but that of atracurium by only $29 \%$. Vecuronium, but not atracurium, infusion rate was found to decrease also in the control group during the second 90 -min study period. These findings appear to be related to the pharmacokinetic differences of these relaxants. The elimination half-life of vecuronium is considerably longer (approximately $70 \mathrm{~min}$ ) than that of atracurium (approximately $20 \mathrm{~min}$ ). Therefore steadystate will be achieved earlier during atracurium than during vecuronium infusion. ${ }^{2}$ It has been demonstrated that long-acting neuromuscular blocking drugs are potentiated more by volatile anaesthetics than are the intermediateacting relaxants. ${ }^{1}$ During long infusions the interaction between enflurane and vecuronium is obviously very similar to the interactions observed between enflurane and long-acting drugs with long elimination 
half-lives, e.g., pancuronium or d-tubocurarine. Thus, the magnitude and nature of the interaction between vecuronium and enflurane may be related to the pharmacokinetic and not to the pharmacodynamic properties of vecuronium.

The computer-controlled infusion of atracurium kept the desired degree of neuromuscular blockade at a reasonably constant level. There were only minor differences of less than $1 \%$ in the mean offset from the set-point values among the groups. This allowed quantification of the interaction between atracurium and enflurane. Neuromuscular blockade was measured by EMG, although it has been criticized because it does not measure events taking place beyond the endplate and because of the sometimes incomplete recovery of $T_{1}$. However, previous investigations have demonstrated that regardless of whether EMG or mechanomyography has been used to measure neuromuscular blockade, they have yielded similar results. ${ }^{4,6,12,13}$ In the present study the feedback signal from the Relaxograph ${ }^{\circledR}$ remained stable throughout the three-hour study period as could be seen in the infusion requirements of atracurium in the control group; atracurium requirements did not change during the study period.

The extent of the interaction of muscle relaxants and inhalation anaesthetics depends both on the neuromuscular blocking drug and the volatile anaesthetic. ' Several studies have compared the potency of atracurium under differrent anaesthetic conditions. Sokoll et al. ${ }^{14}$ found that 1.25 MAC of isoflurane-nitrous oxide anaesthesia decreased the $\mathrm{ED}_{50}$ for atracurium by $40 \%$ compared with fentanyl-nitrous oxide anaesthesia. Rupp et al. ${ }^{15,16} \mathrm{com}-$ pared by $E D_{50}$-values of atracurium under fentanylnitrous oxide and 1.25 MAC of halothane-, enfluraneand isoflurane-nitrous oxide anaesthesia. The potency of atracurium was no more than $20 \%$ lower with enflurane or isoflurane than with fentanyl-nitrous oxide anaesthesia. Halothane did not change the potency of atracurium. These findings are in good agreement with the present study, in which 0.8-1.2 MAC of enflurane-nitrous oxide anaesthesia decreased atracurium infusion requirements by $20-29 \%$.

O'Hara et al. $^{4}$ studied the effects of enflurane, isoflurane, halothane and morphine-nitrous oxide anaesthesia on atracurium infusion requirements. During morphinenitrous oxide anaesthesia, the mean infusion rate of atracurium to maintain the neuromuscular blockade at $90 \%$ was $5.7 \mu \mathrm{g} \cdot \mathrm{kg}^{-1} \cdot \mathrm{min}^{-1}$. One MAC of halothane, enflurane and isoflurane reduced the requirements to 4.9 , 3.5 and $4.1 \mu \mathrm{g} \cdot \mathrm{kg}^{-1} \cdot \mathrm{min}^{-1}$ respectively. Thus, 1 MAC of enflurane reduced atracurium requirements by almost $40 \%$ which appears to fit well with the results of the present study where the end-tidal enflurane concentrations were considerably lower than 1 MAC of enflurane. Similar results have been obtained by Goudsouzian $e t$ al. $^{\mathrm{s}}$ who found that $2 \%$ enflurane inspired concentration, decreased the infusion requirements of atracurium by almost $50 \%$ compared with halothane-nitrous oxide or morphine-nitrous oxide anaesthesia in children.

It has been shown that the interaction between volatile anaesthetics and muscle relaxants is a time-dependent phenomenon. ${ }^{6,12,17,18}$ Withington et al. ${ }^{6}$ showed that the interaction of atracurium and enflurane is negligible during procedures of less than $45 \mathrm{~min}$, but the degree of potentiation increased between 45 and 120 min after administration of enflurane. We studied the interaction of atracurium and enflurane for $90 \mathrm{~min}$, but were not able to repeat this finding. In the study of Withington et al. the infusion rate of atracurium needed to maintain $90 \%$ neuromuscular blockade was found to decrease immediately after the administration of 1 MAC of enflurane was started and was then maintained constant at 50-60\% of the control level for the remainder of the 120 -min study time. This finding is similar to our study. During the second 90-min study period when enflurane was administered, the cumulative dose requirements of atracurium calculated at 30-min intervals did not decrease in any of the study groups after the initial 30 -min period. Another interesting finding in the study of Withington $e t$ al. was that despite the stable infusion rate of atracurium, the concentration needed to produce $90 \%$ neuromuscular blockade during enflurane anaesthesia decreased throughout the study time. This could indicate that enflurane increased the clearance of atracurium; indeed, Parker $\boldsymbol{e t}$ $a .^{19}$ have observed that isoflurane anaesthesia increases the clearance of etracurium. If the effect of enflurane on the pharmacokinetics of atracurium is similar to that of isoflurane, it would explain the apparent discrepancy in the study of Withington et al. If enflurane increased the clearance of atracurium, this would indicate that the concentrations of atracurium necessary for constant $90 \%$ neuromuscular blockade would be lower and thus the atracurium-enflurane interaction is greater than can be predicted from the calculated steady-state infusion rates. For quantifying the interaction of volatile anaesthetics with neuromuscular blocking agents, our methodology assumes that the clearance of atracurium is independent of enflurane administration.

To our knowledge, the effect of different levels of enflurane anaesthesia on the infusion requirements of atracurium has not been studied previously. The previous studies which have quantified the potentiation of muscle relaxants by different concentrations of volatile anaesthetics were done by comparing the $\mathrm{ED}_{50}$-doses. Miller $e t$ $a l .^{20}$ found that the degree of neuromuscular blockade produced by pancuronium and d-tubocurarine was directly 
related to alveolar concentrations of halothane and isoflurane. Rupp et al. ${ }^{21}$ quantified the effect of enflurane, isoflurane and halothane on the neuromuscular blockade produced by vecuronium. Increasing the concentration of the inhalation anaesthetic from 1.2 to $2.2 \mathrm{MAC}$ decreased the $\mathrm{ED}_{50}$ of vecuronium $51 \%$ for enflurane, $33 \%$ for isoflurane and $18 \%$ for halothane. The present study demonstrates that during continous infusion of atracurium the potentiation of atracurium by enflurane is also linearly dependent on the end-tidal enflurane concentration.

The interaction between volatile anaesthetics and muscle relaxants is clinically important. This study shows that enflurane potentiates atracurium in a dose-dependent manner and the infusion rate of atracurium must be decreased when used together with enflurane. The potentiation seems to be less than with vecuronium or longacting relaxants and the interindividual differences in the extent of the interaction are large.

\section{References}

1 Miller RD, Savarese JJ. Pharmacology of muscle relaxants and their antagonists. In: Miller RD (Ed.). Anesthesia, 3rd ed., New York: Churchill Livingstone Inc., 1990: $389-435$.

2 Miller RD, Rupp SM, Fisher DM, Cronnelly R, Fahey $M R$, Sohn YJ. Clinical pharmacology of vecuronium and atracurium. Anesthesiology 1984; 61: 444-53.

3 Brandom BW, Cook DR, Woelfel SK, Rudd GD, Fehr B, Lineberry $C G$. Atracurium infusion requirements in children during halothane, isoflurane, and narcotic anesthesia. Anesth Analg 1985; 64: 471-6.

4 O'Hara DA, Derbyshire GJ, Overdyk FJ, Bogen DK, Marshall $B E$. Closed-loop infusion of atracurium with four different anesthetic techniques. Anesthesiology 1991; 74: 258-63.

5 Goudsouzian N, Martyn J, Rudd GD, Liu LMP, Lineberry $C G$. Continuous infusion of atracurium in children. Anesthesiology 1986; 64: 171-4.

6 Withington DE, Donati F, Bevan DR, Varin F. Potentiation of atracurium neuromuscular blockade by enflurane: time-course of effect. Anesth Analg 1991; 72: 469-73.

7 Schwilden $H$. Optimierung der Dosierung volatiler Anästhetika auf der Grundlage pharmakokinetischdynamischer Modelle. Anästhesie Intensivtherapie Notfallmedizin 1985; 20: 307-15.

8 Olkkola KT, Schwilden H. Quantitation of the interaction between atracurium and succinylcholine using closed-loop feedback control of infusion of atracurium. Anesthesiology 1990; 73: 614-8.

9 Olkkola KT, Schwilden H, Apffelstaedt C. Model-based adaptive closed-loop feedback control of atracurium- induced neuromuscular blockade. Acta Anaesthesiol Scand 1991; 35: 420-3.

10 Keéri-Szanto $M$. Drug consumption during thiopentonenitrous oxide-relaxant anaesthesia: the preparation and interpretation of time/dose curves. Br J Anaesth 1960; 32: 415-23.

11 Olkkola KT, Kansanaho $M$. Quantifying the interaction of vecuronium with enflurane using closed-loop feedback control of vecuronium infusion. Acta Anaesthesiol Scand (in press).

12 Shanks $C A$, Fragen RJ, Ling D. Continuous intravenous infusion of rocuronium (ORG 9426) in patients receiving balanced, enflurane or isoflurane anesthesia. Anesthesiology 1993; 78: 649-51.

13 Olkkola KT, Tammisto T. Quantifying the interaction of rocuronium (Org 9426) with etomidate, fentanyl, midazolam, propofol, thiopental, and isoflurane using closed-loop feedback control of rocuronium infusion. Anesth Analg 1994; 78: 691-6.

14 Sokoll MD, Gergis SD, Mehta $M$, Ali NM, Lineberry $C$. Safety and efficacy of atracurium (BW33A) in surgical patients receiving balanced or isoflurane anesthesia. Anesthesiology 1983; 58: 450-5.

15 Rupp SM, Fahey MR, Miller RD. Neuromuscular and cardiovascular effects of atracurium during nitrous oxidefentanyl and nitrous oxide-isoflurane anaesthesia. $\mathrm{Br} \mathrm{J}$ Anaesth 1983; 55: 67S-70S.

16 Rupp SM, McChristian JW, Miller RD. Neuromuscular effects of atracurium during halothane-nitrous oxide and enflurane-nitrous oxide anesthesia in humans. Anesthesiology 1985; 63: 16-9.

17 Stanski DR, Ham J, Miller RD, Sheiner LB. Timedependent increase in sensitivity to d-tubocurarine during enflurane anesthesia in man. Anesthesiology 1980; 52: 483-7.

18 Wirtanuori $K$, Meretoja OA, Taivainen T, Olkkola KT. Time course of potentiation of halothane and isoflurane on mivacurium infusion. Anesthesiology 1993; 79: A939.

19 Parker CJR, Hunter JM, Snowdon SL. Effect of age, sex and anaesthetic technique on the pharmacokinetics of atracurium. Br J Anaesth 1992; 69: 439-43.

20 Miller RD, Way WL, Dolan MW, Stevens WC, Eger EI II. The dependence of pancuronium- and d-tubocurarineinduced neuromuscular blockades on alveolar concentrations of halothane and Forane. Anesthesiology 1972; 37: 573-81.

21 Rupp SM, Miller RD, Gencarelli PJ. Vecuronium-induced neuromuscular blockade during enflurane, isoflurane, and halothane anesthesia in humans. Anesthesiology 1984; 60: 102-5. 